\title{
CORRIGENDA
}

\section{Regulation of osteosarcoma cell lung metastasis by the c-Fos/AP-1 target FGFR1}

D Weekes, TG Kashima, C Zandueta, N Perurena, DP Thomas, A Sunters, C Vuillier, A Bozec, E El-Emir, I Miletich, A Patiño-Garcia, F Lecanda and AE Grigoriadis

Oncogene (2016) 35, 2948; doi:10.1038/onc.2015.420

Correction to: Oncogene (2016) 35, 2852-2861; doi:10.1038/ onc.2015.344; published online 21 September 2015

Following the online publication of this article the authors noticed an error in one of the subheadings under the Results section.

'Pharmacological inhibition of FGFR signalling promotes osteosarcoma metastasis in vivo' has now been corrected to
'Pharmacological inhibition of FGFR signalling inhibits osteosarcoma metastasis in vivo'.

The authors apologise for any inconvenience caused by this error.

This error has now been rectified, and the corrected article appears in this issue. The html and online pdf versions have also been rectified, and now carry the corrected paper.

\section{The HSP90 inhibitor, 17AAG, protects the intestinal stem cell niche and inhibits graft versus host disease development}

A-L Joly, A Deepti, A Seignez, A Goloudina, S Hebrard, E Schmitt, S Richaud, E Fourmaux, A Hammann, A Collura, M Svrcek, G Jego, E Robinet, E Solary, O Demidov, E Kohli and C Garrido

Oncogene (2016) 35, 2948; doi:10.1038/onc.2016.63

Correction to: Oncogene (2016) 35, 2842-2851; doi:10.1038/ onc.2015.242; published online 14 September 2015

Since the online publication of this article the authors noticed an error in one of the author affiliations. Affiliation 1 should read as follows:

INSERM UMR 866, «Equipe labellisée» Ligue National contre le Cancer and Laboratoire d'Excellence LipSTIC, Dijon, France
The authors apologise for any inconvenience caused by this error.

This error has now been rectified, and the corrected article appears in this issue. The html and online pdf versions have also been rectified, and now carry the corrected paper. 